\title{
CONTRATO DE ARRENDAMIENTO DE VIVIENDA CON PROMESA DE COMPRAVENTA
}

\author{
Roberto Medina Infante \\ María Antonieta Medina Lebel \\ Abogados
}

El 27 de Diciembre de 1993 fue publicada la Ley 19.281 que estableció el "arrendamiento de viviendas con promesa de compraventa", modificándose ésta por la 19.401, publicada en el Diario Oficial de 28 de Agosto de 1995.

Es nuestra intención dar una mirada somera a las principales características de estas disposiciones legales, que representan un nuevo esfuerzo de las autoridades para aumentar el abanico de alternativas de financiamiento habitacional. De esta manera, el "arrendamiento de viviendas con promesa de compraventa" entra a competir con otras fórmulas de financiamiento para la adquisición de viviendas, tales como letras hipotecarias, mutuo hipotecario, etc.

Las leyes 19.281 y 19.401 , ya citadas, fueron complementadas por varios reglamentos, que detallan aspectos tratados en Títulos de las leyes indicadas. Tales son, por ejemplo, el Decreto Supremo No 120, de 15 de Diciembre de 1995, que reglamentó los títulos III, IV y V de la Ley 19.281 y el Decreto Supremo $N^{\circ} 1.334$ que reglamentó los títulos I, II y VI de la misma ley. Sin perjuicio de ello, las Superintendencias de Valores y Seguros y de Seguridad Social han emitido varias, circulares atingentes al tema, cuyo detalle, sin dejar de ser importante, escapa al carácter general de este estudio.

El esquema ideado para el funcionamiento del sistema, que se ha denominado "leasing habitacional", permite la posibilidad de observarlo desde distintos puntos de vista jurídicos ya que es tal el conjunto de instituciones, procedimientos y alternativas, que la descripción pormenorizada de cada una nos llevaría a una extensión que escaparía a los propósitos generales de información que nos hemos señalado como meta. El objeto de este trabajo es sólo referirse, en general, al "esquema" legal y financiero creado por la normativa legal ya indicada. La pormenorización de cada uno de esos aspectos y detalles de su implementación podrá ser objeto de análisis posteriores.

En general, el "arrendamiento de viviendas con promesa de compraventa" es un sistema que permite que una persona natural arriende o prometa arrendar a una "sociedad inmobiliaria" una vivienda, (nueva o usada, terminada a en construcción), prometiendo adquirirla una vez cumplido el plazo acordado y ahorrado el precio pactado. Tratándose de operaciones acogidas a subsidio habitacional, las viviendas sólo podrán ser de las acogidas al D.F.L. 2 de 1959 o sociales a que se refiere del D.L. № 2.552 de 1979, (de un valor de hasta 400 unidades de fomento o construidas con anterioridad al D.F.L. N ${ }^{\circ} 2$ de 1959), que cumplan con determinados requisitos explicados en la Ordenanza General de Urbanismo y Construcciones. 
Para un entendimiento de algunas de las modalidades del "leasing habitacional", incluimos en este trabajo un esquema de su "organigrama" por el cual pretendemos graficar la participación de las distintas entidades, cada una de las cuales aparta su esfuerzo para dar fluidez al sistema. (ver pagina plegable).

Como puede observarse del gráfico transcrito, la operación del "arrendamiento de viviendas con promesa de compraventa excede de la mera relación "empresa de leasing habitacional" y "cliente" o "interesado". Aparecen, además, el Ministerio de la Vivienda, (cuando se opera con subsidio), las "Instituciones", (bancos, sociedades financieras y cajas de compensación familiar que abren y mantienen las Cuentas de Ahorro), sociedades administradoras de fondos para la vivienda, (A.F.V.), "compañías de seguros", "sociedades securitizadoras", "empresas constructoras" e "inversionistas", (Fondos de pensiones, inversionistas institucionales, etc.).

De todo este sistema jurídico-financiero surgen interrogantes, algunas de las cuales pretenderemos responder:

¿Cómo entiende un particular, o en qué le afecta, toda esta institucionalidad? Podríamos decir que, en general, sólo le interesa parte de este sistema pero sí lo afecta en su totalidad. ra?

¿Cuáles son los distintos pasos o etapas de esta compleja red jurídica y financie-

\section{Vamos por partes:}

Primero:- Empecemos por lo más simple. Un particular, (el esquema es accesible sólo a la adquisición de viviendas por personas naturales), tiene interés en adquirir una vivienda a la cual no tiene acceso por no contar con el porcentaje del precio que se le exige pagar al contado. Pudiere ser que tampoco se interese en la compra de una vivienda sino en el arrendamiento, pensando en la posibilidad de movilidad habitacional, es decir, que cuando tenga la capacidad para adquirir una vivienda de mayor valor, poder cambiase a esta otra, imputando a la segunda vivienda lo pagado por la primera.

Decidida por el interesado la adquisición de la vivienda por el sistema de "arrendamiento con promesa de compraventa" recurrirá a una de las "empresas inmobiliarias", comúnmente denominadas de "leasing habitacional" donde solicitará que esa entidad la adquiera a su propietario. Estas "sociedades inmobiliarias", definidas en el artículo 11 de la Ley 19.281 como ".,. aquellas que tengan por objeto la adquisición o construcción de viviendas para darlas en arrendamiento con promesa de compraventa" son, conforme a lo determinado por la Superintendencia de Valores y Seguros, sociedades "de giro exclusivo".

Cumplidos los requisitos de renta del interesado, firma de los contratos de resguardo correspondientes y los otros que sean del caso, la "empresa de leasing habitacional" adquirirá, para sí, la vivienda que desea el cliente.

En este punto debemos hacer un paréntesis, en el sentido que, para que pueda operar una "empresa de leasing habitacional", es menester el cumplimiento de estrictos requisitos, entre ellos, la inscripción en la Superintendencia de Valores y Seguros;

Segundo: Adquirida por la "empresa de leasing habitacional la vivienda deseada por el cliente, se celebra el "contrato de arrendamiento de vivienda con promesa de 


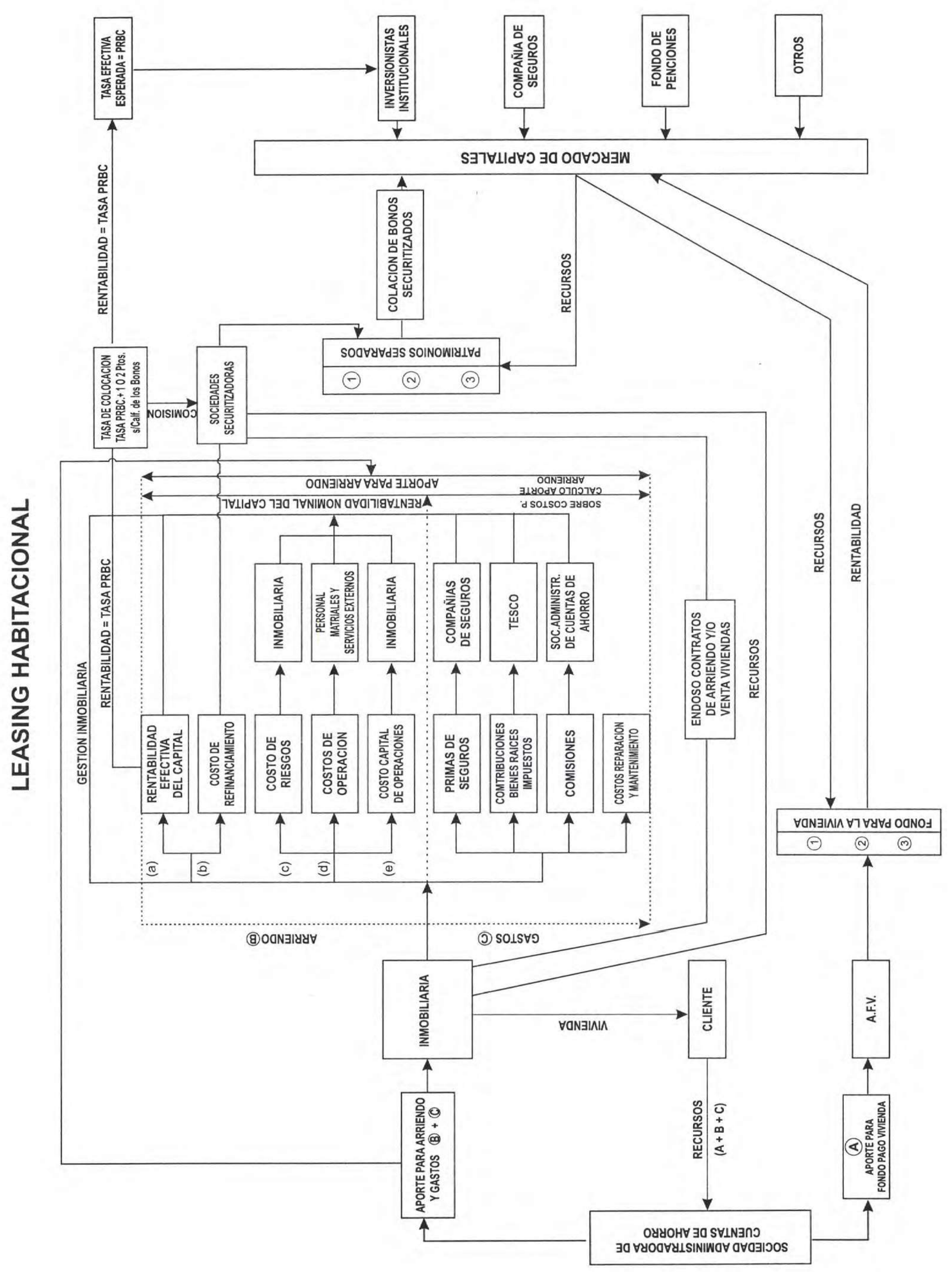


compraventa" entre la "propietaria", es decir, la "inmobiliaria", "arrendadora promitente vendedora" y "el cliente" como "arrendatario promitente comprador".

Este contrato tiene varias características que es conveniente destacar :

2.1. Para algunos, el contrato creado por la ley..... es "de arrendamiento de vivienda con promesa de compraventa", es decir, un solo contrato, con características propias de esta combinación. Para otros, en cambio, la ley ha reconocido la coexistencia de dos contratos, el uno "de arrendamiento" y el otro, "promesa de compraventa", estableciendo disposiciones comunes y particulares a ambos; a nuestro juicio, discutir si es uno u otro, no tiene mayor relevancia jurídica;

2.2. De acuerdo con el artículo 52 de la ley 19.439, es posible que la relación contractual esté diseñada en dos instrumentos separados pero complementarios; uno, que contiene las "normas de general aplicación a los contratos de arrendamiento de viviendas con promesa de compraventa" y el otro, "el particular", que se otorga con cada "arrendatario promitente comprador".

En el primero, que se extiende sin intervención del cliente, se contempla toda la normativa de detalle. Este "contrato general" se inscribe en el Registro de Hipotecas y Gravámenes del Conservador de Bienes Raíces del lugar en que se encuentra ubicada la vivienda.

En el segundo, es decir "el particular", (en la jerga del negocio), se establecen las normas o cláusulas pertinentes para cada operación individual. En este convenio se indica que las normas del "contrato general" quedan incorporados en este "particular". Se inscribe en el mismo registro ya citado, tomándose nota al margen de la inscripción de dominio pertinente. Con la entrega material de la vivienda termina de conformarse la relación entre "cliente", (arrendatario promitente comprador) y empresa de leasing" o "inmobiliaria", (arrendador promitente vendedor).

La principal obligación asumida por "el arrendatario promitente comprador" es cumplir con el pago de su "aporte", es decir, una suma mensual, (en el cual se incluyen rentas de arrendamiento, pago de seguros, provisión de fondos para el precio de la vivienda, etc.), con lo cual, al final del plazo, a antes si se ha completado el valor convenido, podrá suscribir su contrato definitivo;

Tercero: Tenemos, en consecuencia, al arrendatario promitente comprador" en posesión material de la vivienda y al "arrendador promitente vendedor" con el contrato de arrendamiento con promesa de compraventa.

Que sigue:

Cuarto: Con relación al "arrendatario promitente comprador", para dar forma al contrato debió tener una "cuenta de ahorro para el arrendamiento de viviendas con promesa de compraventa" que puede ser abierta en un Banco, en una Sociedad Financiera o en una Caja de Compensación. El objeto exclusivo de esta "cuenta" es la de acumular fondos suficientes para pagar la renta de arrendamiento, para el pago de seguros y gastos y para financiar la compra de la vivienda acordada. La apertura de esta cuenta debe ser anterior al contrato de arrendamiento vivienda con promesa de compraventa y el interesado puede tener, cuantas desee en las instituciones que elija, pudiendo cambiarse libremente hasta dos veces al año. Sin perjuicio de ello, los "arrendatarios" pueden pactar el entero de su "aporte" en forma directa a la sociedad 
inmobiliaria. (El cuadro que reprodujéramos más atrás no contempla la posibilidad de pago directo).

Conviene precisar que el interesado tiene, antes de la celebración del contrato de arrendamiento con promesa de compraventa, la alternativa de celebrar con "las instituciones", (bancos, sociedades financieras o cajas de compensación), un contrato de ahorro voluntario o un contrato de ahorra metódico. Por el primero sólo se abre, (una a más cuentas), sin que para ello sea necesaria vinculación con un contrato de arrendamiento de vivienda con promesa de compraventa. Los aportes depositados en ella pueden tener la finalidad de adquirir viviendas $u$ otra propósito cualesquiera; en tanto que el "metódico" obliga al interesado a efectuar aportes periódicos por el equivalente a un porcentaje del precio de la compraventa acordada, expresado en unidades de fomento, no pudiendo retirar estos aportes sino una vez transcurridos cinco anos. Como se podrá observar, el contrato de ahorro metódica es más específico.

Tratándose de operaciones con subsidio habitacional, el compromiso de aporte a la cuenta de ahorro metódico no puede exceder a un $25 \%$ de la renta mensual del aportante, incluyéndose en ella la del aval o codeudor solidario.

Quinto: Las alternativas que pueden pactar las partes, en el sentido que el "arrendatario promitente comprador" deposite los fondos en su cuenta de ahorro o deposite sus "aportes" directamente en la "sociedad inmobiliaria", producen efectos distintos en el contrato.

\section{En efecto:}

Si se opta por el depósito del "aporte" en la cuenta de ahorro, (abierta en un banco, sociedad financiera a caja de compensación de asignación familiar, conforme al artículo 19 de la Ley 19.291), obliga a que, pagada la renta de arrendamiento y los gastos, el saldo de esas fondos sea entregado a una "sociedad administradora de cuentas de ahorro",(A.F.V.), la que deberá preocuparse de obtener la máxima rentabilidad de ellos a objeto de incrementar los recursos destinados al pago de la vivienda. Los procedimientos para la operación de los "Fondos para la Vivienda" y las "Sociedades Administradoras" están expresados en los artículos 54 y siguientes de la Ley 19.281. Estas sociedades anónimas son de "objeto exclusivo", conforme al artículo 55, y a ellas les corresponde la administración de "los fondos disponibles de los recursos depositados en las cuentas de ahorro para el arrendamiento de viviendas con promesa de compraventa, para su inversión en los valores señalados en la ley". Los fondos se expresan en cuotas y' estas podrán tener un mayor a menor valor de acuerdo con la calidad de administración que, respecto de los fondos, ejerza la "sociedad administradora". (Observemos el parecido con el sistema de las Administradoras de Fondos de Pensiones).

Para terminar con este punto, de la más a menos eficiente administración que se haga de estas fondos, será menor o mayor el esfuerzo que el "arrendatario promitente comprador" tenga que hacer para completar el precio total de la vivienda; en efecto, la mayor valorización de las cuotas del fondo significará un aumento de los recursos disponibles para el interesado y, a la inversa.

Sexto: Examinada ya la situación del "arrendatario promitente comprador", veamos que pasa con el "contrato de arrendamiento con promesa de compraventa", que se encuentra, como la dijimos, en manos de la "sociedad Inmobiliaria". Básicamen- 
te, ésta tiene dos opciones, la primera, mantener los contratos en su poder, (lo que sucederá cuando tenga recursos financieros suficientes para continuar adquiriendo viviendas, arrendándolas y recuperando su valor en el largo plazo, y de esta manera lograr toda la utilidad del negocio), o negociar dichos contratos para los efectos de obtener fondos frescos para continuar con su operación.

La primera alternativa no presenta mayores problemas. Con referencia a la segunda, en el caso de optar por ella, deberá entrar en relación con una de las varias "sociedades securitizadoras" : éstas, reguladas por el Título XVIII de la Ley 18.045 son sociedades anónimas especiales y su objeto exclusivo será "la adquisición de los créditos que señala la ley o que autorice la Superintendencia de Valores y Seguros y la emisión de títulos de deuda, de corto o largo plazo."

La "sociedad inmobiliaria" Ilevará los contratos de arrendamiento con promesa de compraventa a una de estas "sociedades securitizadoras" las que podrán o adquirir las viviendas arrendadas con promesa de compraventa conjuntamente con los contratos de arrendamiento con promesa de compraventa o los flujos de estos contratos. Esta posibilidad de venta de la vivienda está vedada en el caso que "arrendatario promitente comprador" y la "sociedad inmobiliaria" hubieren pactado el pago directo del aporte a ésta.

En el fondo, la operación con la "sociedad securitizadora" implica una gestión financiera en virtud de la cual, previa precio, (representado por el descuento de un porcentaje de los valores a recibir), se entrega a la "sociedad inmobiliaria" los valores presentes adquiriendo la "securitizadora" el derecho a cobrar los valores futuros.

Ahora bien, la "sociedad securitizadora", contando con el respaldo de los contratos y de los flujos provenientes de ellos, emite bonos regulados por el Titulo XVI de la ley 18.045, "cuyos montos y épocas de amortización sean concordantes con los plazos y flujos de ingresos contenidos en los contratos de arrendamiento con promesa de compraventa que suscriben y formen parte de su archivo." (articulo 17, inciso primero de la Ley 19.281).

Estos bonos serán colocados en el mercado de capitales y adquiridas por inversionistas institucionales, compañías de seguros, fondos de pensiones u otros.

De la lectura de lo indicado, vemos como se va creando una cadena de flujos de recursos, (de la cual, como dijimos, es ajeno el arrendatario promitente comprador), lo que permite el financiamiento del sistema; $y$

octavo: Para terminar, nos agradaría referirnos a tres aspectos:

8.1.- Subsidio habitacional;

8.2.- Puesta en marcha del sistema; y

8.3.- Realidad actual.

Veámoslos separadamente:

8.1.- Subsidio habitacional: El Estado, en su política de favorecer la obtención de la casa propia, determinó coadyudar al interesado en la adquisición de ella mediante el subsidio habitacional. En general, el sistema para la asignación de los recursos es semejante al tradicional, con la salvedad que se paga mediante depósito trimestral en la 
cuenta de ahorro para la vivienda o con pago directo a la "sociedad inmobiliaria". La reglamentación para la operativa de pago de la "cuota periódica" del subsidio se estableció en los artículos 45 y siguientes de la Ley 19.281;

8.2. - Puesta en marcha del sistema: Como todo sistema nuevo, la puesta en marcha ha sido lenta. La implementación del aparataje financiero obligó al Estado a intervenir prestando el apoyo a las sociedades inmobiliarias" y lo hizo obteniendo fondos de la Agencia Internacional de Desarrollo, a través de la Corporación de Fomento de la Producción, los que licitó entre las "sociedades inmobiliarias" interesadas en la obtención de estos capitales semilla"; y

8.3.- Realidad actual: Es conveniente hacer un análisis somero de cual es la situación actual del sistema del "leasing habitacional".

El sistema del "leasing habitacional" fue creado para permitir el acceso a la vivienda a sectores que se encuentran en imposibilidad económica de acceder a ella por no disponer de los recursos suficientes demandados por los sistemas tradicionales de financiamiento. Durante el período de estudio de la Ley se crearon falsas expectativas a los interesados que, en la práctica, no se han concretado.

"Factores externos", es decir, los que afrontan todas las empresas inmobiliarias, han atentado en contra de la plena eficacia del sistema, destacando entre ellos la percepción negativa de varios de los actores que participan en el proceso inmobiliario, entre ellos, la Cámara Chilena de la Construcción. En efecto, en repetidas oportunidades, personeros de ella han manifestado sus críticas por la distancia creada entre expectativas y realidades, siendo pesimistas respecto de la pronta normalización del sistema.

En el mismo esquema del párrafo anterior, cabe destacar la determinación del Ministerio de la Vivienda respecto de la cantidad de subsidios disponibles para este tipo de operaciones. En efecto, en atención a que en el año 1997 se ocupó una parte ínfima de estos recursos, las autoridades procedieron a rebajar el número de subsidios para 1998. Esta medida, que dadas las circunstancias aparece lógica, al ser publicitada, provoca un efecto negativo a los posibles interesados.

A modo de ejemplo, y para los efectos de remarcar la negativa percepción del mercado respecto del "leasing habitacional", debemos destacar lo publicado por el Diario El Mercurio de Santiago, en su edición del Domingo 28 de Diciembre de 1997. en la cual, a modo de broma, coloca entre las películas destacadas en el año 1997 "muerte súbita" dando ese título al "leasing habitacional". Broma aparte, ...cuando el río suena..."

Debemos destacar que, bajo ningún concepto, se objeta o discute la seriedad del sistema, por las numerosas precauciones tomadas por la ley y los controles de las Superintendencias sobre él.

Tanto el Ministerio de la Vivienda como algunas Cajas de Compensación, con el fin de promover la apertura de cuentas de ahorro, hicieron circular folletos con ejemplos numéricos incluyendo montos de arriendo que no respondían a un estudio frío de los alcances del sistema. Este hecho desmotiva a los interesados los que se sienten engañados.

Como segundo factor importante, que ha impedido la marcha normal del sistema del "leasing habitacional" debemos destacar las dificultades en la implementación 
del proceso de "securitización" y sus consecuencias. La negativa percepción de los actores respecto del futuro del sistema ha hecho que las empresas de "securitización" hayan tomado precauciones en el complejo proceso de financiamiento; por ella, los costos de las "sociedades inmobiliarias" en el proceso de recuperación de los activos es elevado por las altas tasas de interés que estas empresas estiman que cobrarán. Como se desconoce cuáles serán las tendencias futuras en materia de tasas de redescuento, ello obliga a precaverse trasladando, a su vez, las altas tasas a sus clientes, las que no son competitivas con las cobradas por otras instituciones que ofrecen alternativas de financiamiento habitacional. Aún más, si consideramos que prácticamente en forma simultánea a la publicación de la Ley $\mathrm{N}^{\circ} 19.281$ y antes que el sistema de Leasing Habitacional se pusiera en marcha, por la gran demora en dar a conocer los reglamentos que complementan la Ley, los bancos e instituciones financieras implementaron sistemas que les permiten financiar hasta el $90 \%$ del valor de las viviendas. Con esto el sistema, antes de nacer, perdió gran parte de su ventaja.

Por último, y no pretendiendo agotar el análisis de los factores externos que han atentado en contra del sistema, debemos destacar las actitudes de los interesados respecto del "leasing habitacional". En efecto, producto de muchos años de promoción, la tendencia de nuestra población es la de adquirir la "casa propia". Las reticencias para la adquisición de viviendas mediante un arrendamiento con promesa de "compraventa", en el cual se está arrendando una casa y se está formando un fondo para pagarla, ha sido difícil de asimilar por los interesados, lo que ha hecho más lenta la implementación del sistema.

A pesar de estos factores que han dificultado el despegue, estamos convencidos que la modalidad de arrendamiento de viviendas con promesa de compraventa se consolidará en el mediano plazo, y llegará a igualar a los actuales sistemas de financiamiento en razón a las ventajas y características que le permitirán servir de apoyo único a la movilidad habitacional. 